\title{
CEFOPERAZONE METAL COMPLEXES: SYNTHESIS AND CHARACTERIZATION
}

\author{
J.R. ANACONA*1, ALINA BRAVO² AND MARIA E. LOPEZ ${ }^{1}$ \\ ${ }^{1}$ Departamento de Química. Universidad de Oriente. Apartado Postal 208. Cumaná. Venezuela \\ ${ }^{2}$ Departamento de Bioanálisis. Universidad de Oriente. Apartado Postal 208. Cumaná. Venezuela
}

(Received: January 4, 2012 - Accepted: September 3, 2012)

\begin{abstract}
Cefoperazone (Hcefopz) interacts with transition metal(II) ions to give $[\mathrm{M}($ cefopz $) \mathrm{Cl}]$ complexes $(\mathrm{M}=\mathrm{Fe}, \mathrm{Co}, \mathrm{Ni}, \mathrm{Cu}$ and $\mathrm{Cd})$ and $[\mathrm{Fe}(\mathrm{cefopz}) \mathrm{Cl}] \mathrm{Cl}$ which were characterized by physicochemical and spectroscopic methods. The spectra indicated that the antibiotics act as monoanionic multidentate $\mathrm{NO}_{3}$ chelating agent towards metal ions, via the amides, and carboxylate and $\mathrm{N}$-azomoiety. The complexes are non-toxic, insoluble in water and common organic solvents and probably have polymeric structures.
\end{abstract}

Keywords cefoperazone sodium; antibiotic; metal complexes; antibacterial activity

\section{INTRODUCTION}

The cephalosporin antibiotics are comprised of several different classes of compounds with dissimilar spectrums of activity and pharmacokinetic profiles. All "true" cephalosporins are derived from cephalosporin $\mathrm{C}$ which is produced from Cephalosporium acremonium. Cephalosporins are usually bactericidal against susceptible bacteria and act by inhibiting mucopeptide synthesis in the cell wall resulting in a defective barrier and an osmotically unstable spheroplast. The exact mechanism for this effect has not been definitively determined, but beta-lactam antibiotics have been shown to bind to several enzymes (carboxypeptidases, transpeptidases, endopeptidases) within the bacterial cytoplasmic membrane that are involved with cell wall synthesis [1-4]. The different affinities that various beta-lactam antibiotics have for these enzymes (also known as penicillin-binding proteins; PBPs) help explain the differences in spectrums of activity of these drugs that are not explained by the influence of beta-lactamases. Like other beta-lactam antibiotics, cephalosporins are generally considered to be more effective against actively growing bacteria. The cephalosporin class of antibiotics is usually divided into three classifications or generations. The third generation cephalosporins retain the gram positive activity of the first and second generation agents, but in comparison, have much expanded gram negative activity $[5,6]$. Cefoperazone belongs to the third generation cephalosporins and in continuation of our work about metal based drugs [7-12] we report here the synthesis and characterization of cefoperazone metal complexes. The chemical structure of cefoperazone monosodium is shown in Figure 1.

\section{EXPERIMENTAL}

Physical methods

The spectra of the ligand and its metal complexes were recorded as $\mathrm{KBr}$ pellets in the $4000-400 \mathrm{~cm}^{-1}$ range with a Perkin-Elmer Series 2000 spectrophotometer. FTIR spectra as polyethylene pellets were registered between $450-120 \mathrm{~cm}^{-1}$ using a Bruker IFS $66 \mathrm{~V}$ spectrophotometer. UV-Vis spectra were recorded using a Perkin-Elmer recording spectrometer. C, H, N and S were analyzed on a LECO CHNS 932 model microanalytical instrument. Metal contents were estimated spectrophotometrically on an atomic absorption spectrometer. The halogen content was determined by combustion of the solid complex $(30 \mathrm{mg})$ in an oxygen flask in the presence of a $\mathrm{KOH}-\mathrm{H}_{2} \mathrm{O}_{2}$ mixture. The halide content was then determined by titration with a standard $\mathrm{Hg}\left(\mathrm{NO}_{3}\right)_{2}$ solution using diphenyl carbazone as an indicator. Thermograms were recorded on a simultaneous thermal analyzer, STA-6000 (Perkin Elmer) instrument at a heating rate of $4^{\circ} \mathrm{C} \min ^{-1}$ up to $200^{\circ} \mathrm{C}$. Magnetic susceptibilities were measured on a Johnson Matthey Susceptibility Balance at room temperature using Pascal's constants for the diamagnetic corrections and mercury(II) tetrathiocyanato-cobaltate(II) as calibrant. EPR spectra were recorded on a Bruker ECS 106 spectrometer by the X-band.

Materials and methods

All chemicals were commercially obtained in their purest form and were used without further purification. Solvents were redistilled by standard techniques before use. The complexes were prepared by mixing cefoperazone sodium salt $(1 \mathrm{mmol})$ and metal salts: $\mathrm{FeCl}_{2} \cdot 4 \mathrm{H}_{2} \mathrm{O}, \mathrm{FeCl}_{3} \cdot 6 \mathrm{H}_{2} \mathrm{O}, \mathrm{CoCl}_{2} \cdot 6 \mathrm{H}_{2} \mathrm{O}$,
$\mathrm{NiCl}_{2} \cdot 6 \mathrm{H}_{2} \mathrm{O}, \mathrm{CuCl}_{2} \cdot 2 \mathrm{H}_{2} \mathrm{O}$ or $\mathrm{CdCl}_{2}(1 \mathrm{mmol})$ in methanol $\left(40 \mathrm{~cm}^{3}\right)$. The reaction mixture was then stirred at room temperature for $c a$. $5 \mathrm{~h}$, and a coloured precipitate formed. The precipitated complexes were filtered off, washed with water, methanol and ether and dried under reduced pressure at room temperature. All syntheses were carried out under a nitrogen atmosphere.

\section{RESULTS AND DISCUSSION}

Cefoperazone has two ionisable groups ( $\mathrm{pKa}=2.55$ and 9.55 ); it thus exists predominantly as a monoanionic at a physiological $\mathrm{pH}$. The elemental analyses (Table 1) agree well with a 1:1 metal to ligand stoichiometry for all the complexes. They are air-stable solids. The mononuclear complexes are coloured, insoluble in water and other common organic solvents such as ethanol, benzene, acetone, acetonitrile and ether but soluble in DMF and DMSO. The general formulae $[\mathrm{M}(\mathrm{cefopz}) \mathrm{Cl}]$ and $[\mathrm{Fe}(\mathrm{cefopz}) \mathrm{Cl}] \mathrm{Cl}$ have been assigned to the complexes. Thermograms of the hydrated metal complexes, provided as supplementary information, indicate endothermic decompositions in the $80-90^{\circ} \mathrm{C}$ range due to the loss of molecules of water of hydration, and also reveal that the complexes are stable with no coordinated water and solvent molecules. Attempts to form complexes of a well-defined stoichiometry, under the above-mentioned conditions, with chromium(III), copper(I), zinc(II), mercury(II) and manganese(II) ions were unsuccessful. The conductivity values measured in DMSO at room temperature fall in the range of nonelectrolytes [13] suggesting that the chloride ion is coordinated to the metal(II) ions. The exception was the iron(III) complex, $[\mathrm{Fe}($ cefopz $) \mathrm{Cl}] \mathrm{Cl}$, which show to be $1: 1$ electrolyte.

\section{IR spectra}

The IR spectra of cefoperazone and its complexes are similar and have been assigned mainly to those specific wavenumbers directly involved in complex formation. The main IR wavenumbers are recorded in Table 2. Generally the ring carbonyl absorption frequency will be shifted to higher wave numbers as the ring becomes more and more strained. Thus, the lactam $v(\mathrm{C}=\mathrm{O})$ and the 2,3 piperazinedione $v(\mathrm{C}=\mathrm{O})$ bands appear at 1750 and $1690 \mathrm{~cm}^{-1}$ respectively in the spectra of cefoperazone and in all the metal complexes [14], the exception was the $[\mathrm{Fe}(\mathrm{cefopz}) \mathrm{Cl}]$ complex which presents the lactam $v(\mathrm{C}=\mathrm{O})$ band at $1710 \mathrm{~cm}^{-1}$. The (amide I) $v(\mathrm{C}=\mathrm{O})$ band of the ligand appears at $1660 \mathrm{~cm}^{-1}$ while the complexes showed a negative shift, at around the $1645-1640 \mathrm{~cm}^{-1}$ range indicating coordination through oxygen [15]. A shift of the amide(II) band towards higher frequencies, indicates nonparticipation of the nitrogen atom in the coordination [16]. All this suggests that coordination of the ligand occurs through the oxygen atom from the amide carbonyl groups rather than the lactam and piperazinedione carbonyl moieties where the shifting was not significant, although the binding through b-lactamic carbonyl group cannot be ruled out in the $[\mathrm{Fe}(\mathrm{cefopz}) \mathrm{Cl}]$ complex. The band at $1610 \mathrm{~cm}^{-1}$, corresponding to the carboxylate asymmetrical stretching, is shifted to higher wavenumbers $\left(1620-1630 \mathrm{~cm}^{-1}\right)$ after complexation with the metal(II) ions, thus indicating coordination through that group. The remaining carboxylate bands, namely $v_{\text {sym }}(\mathrm{COO}), \gamma(\mathrm{COO}), \omega(\mathrm{COO})$ and $\rho(\mathrm{COO})$, formerly at $1400,785,610$ and $530 \mathrm{~cm}^{-1}$, respectively, also change as a result of coordination. Furthermore, a carboxylate ligand can bind to the metal atom either as a monodentate or a bidentate ligand, giving changes in the relative positions of the antisymmetric 
and symmetric stretching vibrations [14]. The IR spectra of the complexes give a separation value of $\Delta v>200 \mathrm{~cm}^{-1}$ suggesting monodentate bonding for the carboxylate group. The presence of (M-N) stretching vibrations in the 450-490 $\mathrm{cm}^{-1}$ range for the metal complexes (absent in the free ligand) provide evidence that the tetrazole moiety is bonded to the metal ion through the nitrogen atom. The coordination of the tetrazole group to the metal ion is not the only explanation of these absorption bands, alternatively the $\mathrm{N}$ atom of the $\mathrm{CONH}$ group could coordinate to the metal ions in solid complexes, however steric constraints prevent coordination of these $\mathrm{N}$ atoms along with the $\mathrm{COO}$ and lactam $\mathrm{CO}$ groups. Furthermore, the $\mathrm{C}-\mathrm{N}-\mathrm{C}$ stretching and the $\mathrm{N}-\mathrm{H}$ stretching vibrations of the $\mathrm{CONH}$ residues observed in free cefoperazone at 1180 and $3240 \mathrm{~cm}^{-1}$ respectively, either do not shift or show a slight shift in all the metal complexes indicating that these $\mathrm{N}$ atoms were not involved in coordination. This result suggests coordination by the ligand as a tetradentate monoanionic $\mathrm{NO}$ chelating agent. The bands in the $350-400 \mathrm{~cm}^{-1}$ region observed in the complexes, and absent in the free cefoperazone, are tentatively assigned to $\mathrm{v}(\mathrm{M}-\mathrm{O})$ vibrations.

Table 1.- Elemental analyses for the complexes.

\begin{tabular}{|c|c|c|c|c|c|c|}
\hline \multirow{2}{*}{ Compound } & \multicolumn{6}{|c|}{ Found (Calcd.) \% } \\
\hline & $\mathrm{C}$ & $\mathrm{N}$ & $\mathrm{H}$ & $\mathrm{S}$ & $\mathrm{Cl}$ & M \\
\hline$[\mathrm{Fe}(\mathrm{cefopz}) \mathrm{Cl}] \mathrm{Cl} .3 \mathrm{H}_{2} \mathrm{O}$ & 36.7 & 15.8 & 3.6 & 7.5 & 8.4 & 6.3 \\
\hline$\left[\mathrm{Fe}\left(\mathrm{C}_{25} \mathrm{H}_{32} \mathrm{~N}_{9} \mathrm{O}_{11} \mathrm{~S}_{2} \mathrm{Cl}_{2}\right)\right]$ & $(36.4)$ & $(15.3)$ & $(3.9)$ & $(7.8)$ & $(8.6)$ & $(6.8)$ \\
\hline$[\mathrm{Fe}(\mathrm{cefopz}) \mathrm{Cl}]$ & 40.5 & 16.9 & 3.3 & 8.8 & 4.5 & 7.7 \\
\hline$\left[\mathrm{Fe}\left(\mathrm{C}_{25} \mathrm{H}_{26} \mathrm{~N}_{9} \mathrm{O}_{8} \mathrm{~S}_{2} \mathrm{Cl}\right)\right]$ & $(40.8)$ & $(17.1$ & (3.6) & (8.7) & (4.8) & (7.6) \\
\hline$[\mathrm{Co}(\mathrm{cefopz}) \mathrm{Cl}] \cdot \mathrm{H}_{2} \mathrm{O}$ & 39.8 & 16.3 & 3.6 & 8.1 & 4.9 & 8.2 \\
\hline$\left[\mathrm{Co}\left(\mathrm{C}_{25} \mathrm{H}_{28} \mathrm{~N}_{9} \mathrm{O}_{9} \mathrm{~S}_{2} \mathrm{Cl}\right]\right.$ & $(39.7)$ & $(16.7)$ & $(3.7)$ & $(8.5)$ & $(4.7)$ & (7.8) \\
\hline$[\mathrm{Ni}($ cefopz)Cl] & 40.4 & 17.5 & 3.8 & 8.3 & 4.6 & 8.4 \\
\hline$\left[\mathrm{Ni}\left(\mathrm{C}_{25} \mathrm{H}_{26} \mathrm{~N}_{9} \mathrm{O}_{8} \mathrm{~S}_{2} \mathrm{Cl}\right)\right]$ & $(40.6)$ & $(17.1)$ & (3.6) & $(8.7)$ & $(4.8)$ & $(8.0)$ \\
\hline$[\mathrm{Cu}($ cefopz $) \mathrm{Cl}] \cdot \mathrm{H}_{2} \mathrm{O}$ & 39.6 & 16.3 & 3.4 & 7.9 & 4.4 & 8.3 \\
\hline$\left[\mathrm{Cu}\left(\mathrm{C}_{25} \mathrm{H}_{28} \mathrm{~N}_{9} \mathrm{O}_{9} \mathrm{~S}_{2} \mathrm{Cl}\right)\right]$ & $(39.4)$ & $(16.6)$ & $(3.7)$ & (8.4) & $(4.7)$ & $(8.4)$ \\
\hline$[\mathrm{Cd}(\mathrm{cefopz}) \mathrm{Cl}]$ & 37.8 & 15.6 & 2.8 & 8.2 & 4.3 & \\
\hline$\left[\mathrm{Cd}\left(\mathrm{C}_{25} \mathrm{H}_{26} \mathrm{~N}_{9} \mathrm{O}_{8} \mathrm{~S}_{2} \mathrm{Cl}\right)\right]$ & $(37.9)$ & $(15.9)$ & (3.3) & $(8.1)$ & $(4.5)$ & \\
\hline
\end{tabular}

\section{Electronic spectra}

The UV-Vis spectra of cefoperazone and its complexes in DMSO present absorption maxima at $255-270 \mathrm{~nm}$ assigned to a $\pi \rightarrow \pi^{*}$ transition due to molecular orbital energy levels originating in the NC-S moiety $[17,18]$. An intraligand band at $290-320 \mathrm{~nm}$ is related to the $\pi \rightarrow \pi^{*}$ transitions within the tetrazole moiety. The band in the $360-380 \mathrm{~nm}$ region is ascribed to an intraligand transition of the $n \rightarrow \pi *$ type in accordance with the literature data for transitions due to sulphur atoms $[17,19]$. The fact that the bands due to sulphur atoms are not shifted suggests that these atoms are not involved in coordination to metal ions. The local symmetry around metal(II) ions may belongs to the point group $\mathrm{C}_{3 \mathrm{v}}$ assuming trigonal bypiramidal geometry, therefore, an accurate band assignment is not possible due to the multicomponent nature of the bands. The iron(III) complex showed very weak absorption bands probably due to spin-orbit forbidden transitions. The iron(II) complex showed two weak bands at 420 and $600 \mathrm{~nm}$. The cobalt(II) complex in DMSO solution presents one absorption maxima at $480 \mathrm{~nm}$ presumably due to intraligand excitation. Because of the insaturation of the cefoperazone, the intense uv absorption has a tail in the visible region and this hampers assignment of the relatively week d-d transitions of the cobalt(II) and iron(II) ions. The nickel(II) complex showed a broad absorption band at 580-650 $\mathrm{nm}$ range attributable to a d-d electronic transition. The copper(II) complex exhibits a d-d transition as a broad band centered at $680 \mathrm{~nm}$ falling in the range of those usually reported for fivecoordinate copper(II) environments [20].

\section{Magnetic measurements}

From the molar magnetic susceptibility values, corrected magnetic moments were calculated using Pascal's constants. The magnitudes of the magnetic moments fall within the ranges associated with high spin ions in octahedral fields and normally they are unlikely to be of value in discriminating between the metal ions in six or five coordinate geometries. The iron(III) complex have a magnetic moment of 5.72 B.M. which is consistent with high spin $\mathrm{d}^{5}$ systems with five unpaired electrons and an $\mathrm{S}=5 / 2$ ground state. The
iron(II) complex has a magnetic moment of 4.65 B.M. which corresponds to a high spin $\mathrm{d}^{6}$ systems with four unpaired electrons and an $\mathrm{S}=2$ ground state. Since the experimental value obtained for the magnetic moment of cobalt(II) in the cobalt(II) complex is $4.12 \mathrm{BM}$. while the calculated value for $\mathrm{a} \mathrm{d}^{7}$ high spin electronic distribution is $3.87 \mathrm{BM}$ we conclude that cobalt(II) in $[\mathrm{Co}(\mathrm{cefopz}) \mathrm{Cl}]$ is in a five coordinate or octahedral geometry with a high spin configuration. The experimental value obtained for the magnetic moment for nickel(II) in [Ni(cefopz)Cl] complex is 3.17 B.M. which is close to the expected value for a five coordinate geometry (3.20-3.40 B.M.) [21]. For [Cu(cefopz) $\mathrm{Cl}$ the experimental magnetic moment measured is equal to $2.22 \mathrm{~B}$.M. while the calculated one for a $\mathrm{d}^{9}$ configuration is equal a 1.73 B.M. suggesting the presence of excess metal ions in the complex. Although lowered moments can be accounted for by antiferromagnetic interactions between the ions, higher moments would require ferromagnetic interactions which are significantly rarer.<smiles>CCN1CCN(C(=O)NC(C(=O)NC2C(=O)N3C(C(=O)O)=C(CSc4nncn4C)CSC23)c2ccc(O)cc2)C(=O)C1=O</smiles>

Figure 1. The structure of cefoperazone anion. 
EPR spectra of a powdered sample of the iron(III) complex at room temperature (RT, $300 \mathrm{~K}$ ) and liquid nitrogen temperature (LNT, $77 \mathrm{~K})$ were obtained, but in each case there was simply a strong broad band with no evidence of fine structures due to ${ }^{57} \mathrm{Fe}(2,25 \%$ natural abundance, $\mathrm{I}=1 / 2)$. The $\mathrm{g}_{\text {iso }}=2.01$ at $\mathrm{RT}$ and 2.02 at LNT probably indicate an octahedral environment around iron(III) [22]. The EPR spectrum at LNT of the powder sample of the copper(II) complex (Figure 2) showed four lines $\left({ }^{63} \mathrm{Cu}, \mathrm{I}=3 / 2\right)$ and is anisotropic at higher magnetic field. The three peaks of low intensity in the weaker field region are considered to originate from the $\mathrm{g}_{\|}$component. The calculated $\mathrm{g}$ values, $\mathrm{g}_{\|}=2.15$ and $\mathrm{g}_{\lambda}=2.05$ and $\mathrm{A}_{\|}=125 \times 10^{-4} \mathrm{~cm}^{-1}$ indicate that the unpaired electron most likely resides in the $\mathrm{d}_{\mathrm{x} 2 \mathrm{y} 2 \mathrm{2}}$ orbital having ${ }^{2} \mathrm{~B}_{1 \mathrm{~g}}$ as a ground state term [23].

Table 2.- IR spectral data of the drug and the complexes $\left(\mathrm{cm}^{-1}\right)$.

\begin{tabular}{|c|c|c|c|c|c|}
\hline Compound & $\begin{array}{l}\nu \mathrm{C}=\mathrm{O} \\
\text { lactam }\end{array}$ & $\begin{array}{c}\nu \mathrm{C}=\mathrm{O} \quad \nu \mathrm{C}=\mathrm{O} \\
\text { dione amide } \mathrm{I}, \mathrm{II}\end{array}$ & $\begin{array}{r}v \mathrm{COO} \\
\text { asymm }\end{array}$ & $\begin{array}{l}\nu \mathrm{COO} \\
\text { symm }\end{array}$ & $\Delta v$ \\
\hline$[\mathrm{Na}(\mathrm{cefopz})]$ & 1750 & 16901660,1530 & & & \\
\hline$[\mathrm{Fe}($ cefopz$) \mathrm{CL}] \mathrm{Cl} .3 \mathrm{H}_{2} \mathrm{O}$ & 1750 & 16901645,1570 & 1600 & 1380 & 220 \\
\hline$[\mathrm{Fe}($ cefopz $) \mathrm{Cl}]$ & 1710 & 16901640,1570 & 1600 & 1380 & 220 \\
\hline$[\mathrm{Co}(\mathrm{cefopz}) \mathrm{Cl}] \cdot \mathrm{H}_{2} \mathrm{O}$ & 1750 & 16901645,1570 & 1600 & 1380 & 220 \\
\hline [Ni(cefopz)Cl] & 1750 & 16901645,1570 & 1600 & 1380 & 220 \\
\hline$[\mathrm{Cu}($ cefopz $) \mathrm{Cl}] \cdot \mathrm{H}_{2} \mathrm{O}$ & 1750 & 16901645,1570 & 1600 & 1380 & 220 \\
\hline$[\mathrm{Cd}($ cefopz $) \mathrm{Cl}]$ & 1750 & 16901640,1570 & 1600 & 1380 & 220 \\
\hline
\end{tabular}

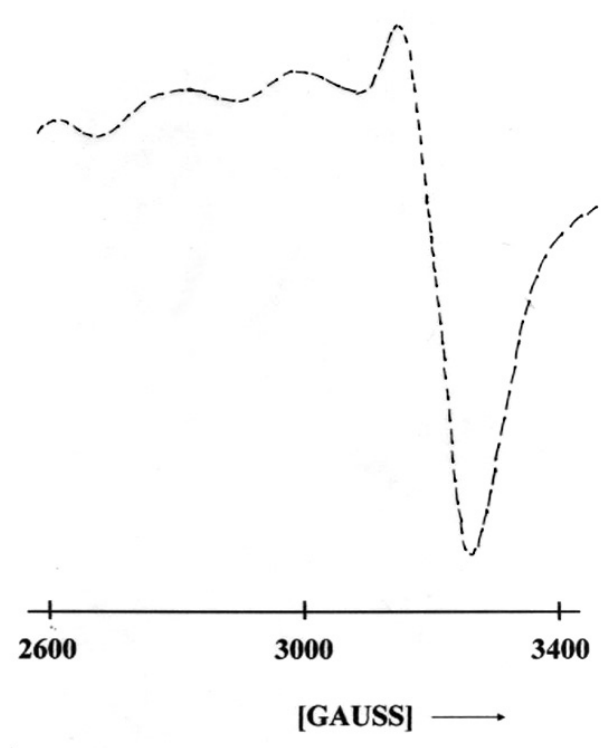

Figure 2. EPR spectrum of cefoperazone copper complex.

Structure of complexes

Despite the crystalline nature of the products, neither proved suitable for $\mathrm{X}$-ray structure determination. The coordination chemistry of some beta-lactam antibiotics with transition and $\mathrm{d}^{10}$ metal ions has been reported [7-12, 24]. In our case, the cefoperazone anion has several potential donor atoms but, due to steric constraints, the ligand can provide a maximum of four donor atoms to any one metal center. The assumption that the coordination of cefoperazone occurs through the carboxylate, amide carbonyl moieties and $\mathrm{N}$-tetrazole atom seems likely from molecular models. It is feasible that the metal ions in the [M(cefopz) $\mathrm{Cl}$ complexes (where $\mathrm{M}=\mathrm{Fe}(\mathrm{II}), \mathrm{Co}(\mathrm{II}), \mathrm{Ni}(\mathrm{II}), \mathrm{Cu}(\mathrm{II})$, and $\mathrm{Cd}(\mathrm{II})$ ) containing one coordinated chloride anion are pentacoordinate and would probably have a tetragonal pyramidal or trigonal bipyramidal geometries. The poor solubilities of the complexes in all but strongly coordinating solvents suggests a polymeric structure, in which the cefoperazone ligand bridge between metal centres. We assume that each cefoperazone is bound to two metal ions (tetrazole ring and carboxylate group is on one $\mathrm{M}$ and the two amide moieties are on another metal ion). Although, it would not be appropriate to predict precisely the structure of these complexes, the structure (Figure 3 ) may tentatively be proposed.

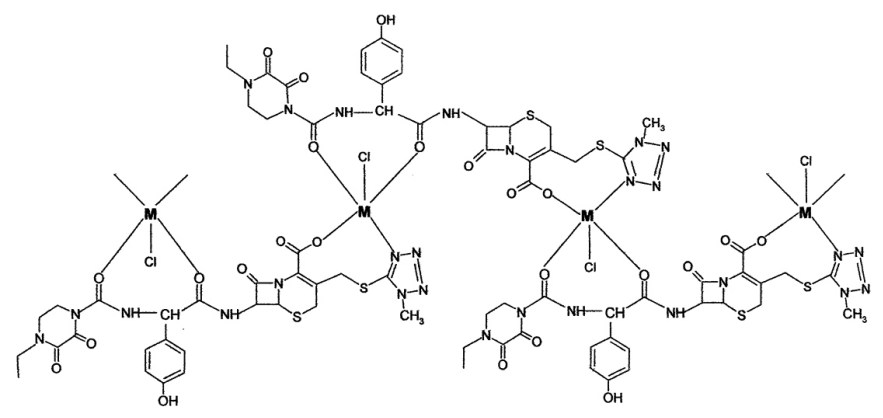

Figure 3. Tentative structure of the cefoperazone metal complexes $[\mathrm{M}($ cefopz $) \mathrm{Cl}],[\mathrm{M}=\mathrm{Fe}, \mathrm{Co}, \mathrm{Ni}, \mathrm{Cu}$ and $\mathrm{Cd}]$.

\section{CONCLUSION}

Cefoperazone complexes with different metal ions of 1:1 metal to antibiotic stoichiometry have been prepared. The coordination to metal occurs through the tetrazole, carboxylate and amide carbonyl groups although the binding through b-lactamic carbonyl group cannot be discarded in the [Fe(cefopz)Cl] complex. The solubility of the cefoperazone complexes in water and common organic solvents is reduced on complexation.

\section{Supplementary information}

Thermograms recorded on a simultaneous thermal analyzer, STA- 6000 (Perkin Elmer) instrument at a heating rate of $4{ }^{\circ} \mathrm{C} \mathrm{min}^{-1}$ up to $200^{\circ} \mathrm{C}$ are available free of charge as PDF file from the authors and the journal.

\section{ACKNOWLEDGEMENTS}

Our sincere thanks to the Comision de Investigacion from the Universidad de Oriente for providing financial support as well as Lic. Erasto Bastardo for elemental analyses.

\section{REFERENCES}

1. Bergan, T. (1987) Drugs, 34, 89-104

2. Cunha, B. (1982) Clin. Ther., 14, 616-652

3. Neu, H. (1987) Drugs, 34, 135-153

4. Williams, D.R. (1971) The Metals of Life, Van Nostrand Reinhold, London

5. Sorenson, J.R.J. (1976) J. Med. Chem., 19, 135-141 
6. Brown, D.H., W.E. Smith \& J.W.Teape (1980) J. Med. Chem. 23, 729-733

7. Anacona J.R. \& I. Rodriguez (2004) J. Coord. Chem. 57, 1263-1269

8. Anacona J.R. \& C.C. Gil (2005) Transition Met. Chem. 30, 605-609

9. Anacona J.R. \& A. Rodriguez (2005) Transition Met. Chem. 30, 897-901

10. Anacona J.R. \& F. Acosta (2006) J. Coord. Chem. 59, 621-627.

11. Anacona J.R. \& J. Estacio (2006) Transition Met. Chem. 31, 227-231

12. Anacona J.R. \& G. Da Silva (2005) J. Chil. Chem. Soc. 50, 447-450

13. Geary, W. (1971) Coord. Chem. Rev. 7, 81-122

14. Socrates, G. (1980) Infrared Characteristic Group Frequencies, John Wiley \& Sons, Ltd. Great Britain

15. Barnes, D.J., R.L. Chapman, F.S. Stephens \& R.S. Vagg (1981) Inorg. Chim. Acta, 51, 155-162

16. Garg, B.S., N. Bhojak, P. Dwivedi \& V. Kumar (1999) Transition Met. Chem.,24, 463-466

17. Franchini, G.C., A. Giusti, C. Preti, L. Tosi \& P. Zannini (1985) Polyhedron, 9, 1553-1558
18. Hadjikostas, C.C., G.A. Katsoulos and S.K. Shakhatreh (1987) Inorg. Chim. Acta, 133, 129-132

19. Castillo, M., J.J. Criado, B. Macias \& M.V. Vaquero (1986) Inorg. Chim. Acta, 124, 127-132

20. Hathaway, B.J. (1987) In: G. Wilkinson, R.D. Gillard and J.A. Cleverty (EDs.), Comprehensive Coordination Chemistry. Pergamon Press, New York

21. Salib, K.A.R., A.A.Saleh, S.A. El-Wafa \& H.F.O. El-Shafiy, (2003) J. Coord. Chem., 56, 283-289

22. Goodwin B.A. \& J.B. Raynor (1970) Adv. Inorg. Chem. Radiochem. 13,135-632

23. Jain, M.C., A.K. Srivastava \& P.C. Jain (1977) Jain, Inorg. Chim. Acta, 23, 199-203

24. Anacona, J,R, (2001) J. Coord. Chem. 54, 355-365 . 